\title{
The positive gains of integration: a qualitative study of GPs' perceptions of their complementary practice
}

Jon Adams Lecturer in Health Social Science, Centre for Clinical Epidemiology and Biostatistics, School of Medical Practice and Population Health, Faculty of Health, University of Newcastle, Royal Newcastle Hospital, Newcastle, Australia

An increasing number of general practitioners (GPs) are personally practising complementary and alternative medicine (CAM) to treat their NHS patients. While research on CAM is beginning to emerge we still know very little about CAM practice in primary care. Researchers have largely concentrated upon exploring CAM consumption and broad orthodox CAM provision. A small body of work has begun to examine CAM practice from the GP therapist's perspective and this work has highlighted the constraints and difficulties associated with CAM integration in general practice. Despite such limitations, direct integration continues apace and this raises the question: what clinical and practice benefits are GPs possibly gaining from CAM integration? This is an area that still lacks focused research attention and this paper, exploring the positive gains of integration as perceived by GP therapists, provides a first stage towards filling this research gap. A study, based upon 25 in-depth interviews with GPs practising CAM, was undertaken to explore GP therapists' understandings and experiences of their complementary practice. This paper presents one area of findings produced from the analysis of the GPs' accounts. Analysis reveals that GP therapists identify a number of positive clinical gains associated with their direct integrative practice. These are: filling gaps and successfully treating conditions for which conventional medicine proves ineffective; providing safer techniques in medical cases where the practitioner suspects or anticipates potential side-effects from conventional treatments; and helping maintain job satisfaction and relieve boredom for the practitioner. These findings are discussed within the context of contemporary CAM provision and consumption and recent circumstances affecting general practice. Set within this context, the findings provide an important addition to our current understanding of the increasingly close relationship between CAM and general practice. In conclusion, it is argued that the positive gains experienced by GPs practising CAM should not be ignored by those considering the future provision and practice of CAM within the general practice environment.

Key words: clinical gains; complementary and alternative medicine (CAM); general practice; GP therapists; integration

\section{Introduction}

The integration of complementary and alternative medicine (CAM) into orthodox healthcare has

\footnotetext{
Address for correspondence: Dr Jon Adams, Lecturer in Health Social Science, Centre for Clinical Epidemiology and Biostatistics, School of Medical Practice and Population Health, Faculty of Health, University of Newcastle, Level 3 David Maddison Building, Royal Newcastle Hospital, Newcastle 2300, New South Wales, Australia. Email: jon.adams@ newcastle.edu.au
}

recently attracted increasing attention (Ernst, 2000; Featherstone and Forsyth, 1997; House of Lords, 2000; Tovey and Adams, 2002; Zollman and Vickers, 1999, 1999a) and general practice is one branch of medicine where CAM integration is making its presence felt (Tovey and Adams, 2001; Peters, 1994). Alongside the less critical stance of the British Medical Association (BMA, 1993) has been a growing level of interest in CAM among general practitioners (GPs) (Botting and Cook, 
2000; Adams, 2000) with a significant number practising CAM to treat their NHS patients (Thomas, Nicholl and Fall, 2001). These developments are taking place amidst a period of substantial change for primary care (Tovey, 2000) with ongoing debate surrounding models of clinical practice, the nature of primary health care teams, the future direction of general medical service provision and the like (Dowell and Neal, 2000).

Accompanying the increasing medical interest in 'other' medicines has emerged a growing body of research on CAM (Tovey and Adams, 2001). This work has tended to focus upon a selection of specific topics (Siahpush, 1999), two main areas being the patterns and trends in CAM consumption and orthodox CAM provision.

\section{CAM consumption}

Numerous studies have charted the trends in CAM consumption both in the UK (e.g., Vincent and Furnham, 1996; Thomas, Nicholl and Coleman, 2001) and other developed countries (e.g., Astin, 1998; Eisenberg et al., 1998; McGregor and Peay, 1996). As well as providing valuable demographic data about CAM users, such work has explored CAM patients' perceptions and motivations for their CAM use. Research suggests that patients tend to use CAM as a supplement to conventional medicine rather than as an alternative treatment option (Berg and Arnetz, 1998); CAM and conventional treatments are widely used on a pragmatic basis with the vast majority of CAM patients visiting their family doctor and complementary practitioner concurrently (Astin, 1998). Studies also identify that many people using complementary treatments report unsuccessful attempts to gain relief from conventional practice (Goldstein and Glik, 1998; McGregor and Peay, 1996) and often seek CAM care due to what they see as the serious side effects of conventional medicines (Verhoef et al., 1998) coupled with what is interpreted as the relative safety of complementary treatments (Siahpush, 1998).

\section{Orthodox CAM provision}

Accompanying the work on CAM consumption has been an exploration of orthodox CAM provision especially within general medical practice (Anderson and Anderson, 1987; Perkin, Pearcy and Fraser, 1994; White, Resch and Ernst, 1997). Survey based projects have charted the level of GP
CAM practice (Wearn and Greenfield, 1998), investigated the characteristics of those GPs practising CAM (Hall and Giles-Corti, 2000; Verhoef and Sutherland, 1995; Visser and Peters, 1990) and/or have provided a preliminary exploration of GP attitudes towards CAM (Goldszmidt et al., 1995; Pirotta et al., 2000).

While these studies are valuable, they do not provide us with any understanding of the clinical reality of CAM integration. To gain such an understanding there is a need to explore qualitative research in the field. A small but growing body of work has begun to explore GP therapists' experiences of direct CAM integration in more depth (Adams, 2001a; Adams, 2001b; Adams and Tovey, 2000; May and Sirur, 1998). A major theme illustrated by this work is the difficulty GPs face when integrating CAM (Adams, 2001b). GP therapists experience time and organizational barriers to their integrated practice with the NHS primary care environment not easily lending itself to the integration of 'time consuming' treatments of CAM (Adams, 2001b). Furthermore, it appears that such barriers are sometimes compounded by a lack of cooperation from nonsupportive practice partners (Adams, 2001b).

Despite such obstacles, direct integration continues apace (Adams and Tovey, 2000). The fact that a significant proportion of GPs are practising CAM in the face of such difficulties raises the important question: what clinical and practice benefits do GPs gain from personally integrating CAM? Unfortunately, this remains an area that has not received focused research attention. In response this paper - exploring GP therapists' perceptions of the positive gains of their CAM integration - provides a first step towards filling this research gap.

\section{Methods}

Reported here is one set of findings from a wider study which explored GP therapists' understandings and experiences of their complementary practice. A short questionnaire was first posted to all the GPs ( $n$ $=918$ ) on the medical registers for the cities of Edinburgh and Glasgow. The questionnaire was employed as a means of identifying GPs practising CAM and data from this stage of the fieldwork was not analysed for the main study.

A response rate of $52.7 \%$ was recorded with the return of 484 questionnaires. From these responses, 
34 doctors agreed to be interviewed of which 28 were practising CAM (three of these GP therapists later declined to be interviewed due to illness or other constraints). Following purposive sampling methods (aiming to select information-rich cases for in-depth study rather than selecting for statistical representation (Fitzpatrick and Boulton, 1994)) only those GPs practising CAM were chosen for interview to best fit the aim and objectives of the research.

Twenty five in-depth interviews were conducted with GPs integrating one or more of the therapies of acupuncture, autogenic training, homeopathy, hypnotherapy and neurolinguistic programming between the summer of 1997 and the spring of 1998 (these therapies were determined by response and not by the researcher prior to recruitment). Fourteen male and 11 female GPs were interviewed. All were currently in group practices of three or more partners, all apart from three had been practising for more than five years and twenty for over ten years in general practice. The therapies practised by the 25 GP therapists interviewed are outlined in Table 1 below.

The interviews were unstructured so as to allow the GPs the flexibility to direct and shape the discussion in line with their focus and concerns (Seale, 1998). Prompts were used only to ask for clarification or expansion of participants' points. Key words and themes as described by the GP were noted and consulted as the interview commenced to further probe GPs' explanations and claims later in the interview.

At the beginning of every interview the researcher outlined their background (social science), how the study developed and the aim of the research. The GPs were also given an opportunity to ask questions or clarify points of concern regarding the study both at the start and end of the

Table 1 Therapies practised by GPs in the study

Therapy

Number of GPs practising

Acupuncture 10

Homeopathy

16

Hypnotherapy

(including autogenic training)

Neurolinguistic programming

12

4 interview. The interviews ranged from between one to two hours in duration. Assurances of confidentiality were given and the interviews audiotaped with the consent of the GPs involved. All tapes were transcribed to computer files shortly following interview. Transcription occurred concurrently with data collection and preliminary analysis throughout the fieldwork period and codes and analytical themes were developed from the transcripts in a cumulative manner.

In order to enhance the reliability of the analysis researcher triangulation was introduced (Rice and Ezzy, 1999) with other qualitative researchers providing independent analysis of selections from the interview transcripts. Issues regarding the coding of the data were then discussed and suggestions fed back into the coding process. In addition, the data was carefully re-examined for evidence of negative cases at regular intervals throughout the coding process to help ensure the internal validity of the findings.

\section{Results}

Analysis of the GP therapists' views of the positive benefits of integrative practice reveals three distinct yet often interrelated themes. These are outlined below:

\section{Filling gaps and the technical fix of complementary treatments}

[T] hey give me more skills to use when standard allopathic medicine has nothing to offer sort of thing... where I use it is for people mainly who've tried allopathic medicine and they're kind of at their wits end and you've got to think of another therapy. (GP 12)

A major theme identified from the GP interviews is the role of CAM in dealing with cases left untreated by conventional medicine; the therapies can provide possible treatment options for those health care problems where conventional medicines fail to help. The GPs explain their CAM as 'a gap filler', 'an extra weapon' or 'another set of tools' for clinical practice. As one GP states in relation to acupuncture:

It provides me with an extra option in treating people, a lot of people come along and there really isn't any other option you can give them and acupuncture can be a new way

(note: some GPs practised more than one therapy)

Primary Health Care Research and Development 2003; 4: 155-162 
of helping them, a different option, a different road to go down, so it's erm, extra kind of, extra weapon in your armamentarium for treating people. (GP 19)

However, this gap filling does not necessarily imply that complementary therapies can cure these selected medical cases, simply that they can provide another avenue of approach when all else has failed. Nevertheless, some GPs do explain how their CAM provides genuine solutions to otherwise untreatable conditions.

[CAM is] what I was doing before but it's sort of added to it. So it's like another, another set of tools that you didn't have before that suddenly a lot of things that were broken can be fixed now that you have the tools for them. (GP 6)

it's such a natural way to take, er, if you're in general practice to go down the route of complementary therapies because they do offer the possibility of lots of relief of symptoms or even cures. In general practice there's so much that you see that is, that you cannot cure. (GP 4)

In addition, some GPs explain how CAM treats problems where physical cause is not identifiable. As one doctor explains:

something like sixty-percent of the patients that come in here have problems as a result of life circumstances more than anything and there's no conventional treatment for it, whereas the homeopathy gets right to it, you know. So it's treating patients that you've always wanted to treat but couldn't. (GP 5)

\section{Safety and reducing side-effects}

Homeopathy is side-effect free. I think that's the big difference with conventional medicine...whereas with homeopathy you know that there aren't going to be any side-effects because you're not really giving very much, so that's a different approach really. (GP 20)

The side-effects of some conventional medicines are a concern for the GPs and this is often contrasted with what they perceive as the safe, natural and noninvasive techniques of CAM. One GP explains his concerns regarding the dangers of conventional treatments and how homeopathy provides a relatively safe clinical option:

I think a lot of our drug therapies you know they say $30 \%$ of patients are in hospital because of iatrogenic illness you know so I think you've got to give something that's not going to harm the patient. Homeopathic remedies don't effectively have side-effects. (GP 12)

Similarly, other GPs highlight the safety of acupuncture. For example GP 2 states:

acupuncture for me is an alternative medicine which has no side-effects, it doesn't bring you out in rashes and there's nothing to be lost there's no harm in it there's no danger in it...I know I'm not doing any harm. It means to me it's something else that I can do to help my patients which is not conventional medicine which I'm happy to do which is no risk. (GP 2)

As we can see from these quotes, the safety of CAM treatments is a primary attraction for initiating integration. However, there is also another way in which CAM can provide these GPs with safer practice. The GPs restrict their practice of CAM to a supplementary add-on role (a point highlighted in their descriptions of gap filling) and, as such, all have on occasion combined the practice of CAM with more conventional treatment. This combined practice is often accompanied by the strategic use of CAM to reduce patient dependency on conventional treatments when there are concerns over side-effects. As one doctor explains in relation to his acupuncture:

I sort of give them acupuncture and try and stop the medication a bit. People who have been on anti-inflammatories for instance who maybe have trouble with their stomach but the anti-inflammatories are the only thing that have helped, ordinary painkillers have not worked and they're starting to get stomach upsets because of their tablets and then I might think well if I give them a course of acupuncture if I can give them prolonged relief then hopefully they can stop their antiinflammatories. (GP 23) 
And another in relation to the practice of homeopathy:

hopefully what you can do is lessen their joint symptoms and their pain and their stiffness and obviously these people are on lots of anti-inflammatory drugs, maybe on steroids as well and what you, what I do aim to do is get the homeopathy in and see if I could lower the amount of other drugs that they're taking. (GP 20)

\section{Relieving boredom and maintaining job satisfaction}

The GPs that I know that enjoy their work most do something a little extra. You know they all have a little something that they do...to not [get] sludged under the onslaught of diarrhoea and sore throats. Acupuncture, hypnotherapy, homeopathy, they can fit that role. There are still a few of us who enjoy our work you don't hear much about them. (GP 19)

Another theme highlighted by the GPs is the ability of CAM to help them maintain interest and job satisfaction. As one doctor states:

in general practice you have a great opportunity not to be bored but nevertheless it can be appallingly boring...you need to find ways of keeping yourself stimulated and interested, the complementary therapies are good for that. (GP 10)

And another outlines the potential difficulties facing GPs:

the situations and the pressures are such that as time goes on they get a bit more cynical and a bit more run down and a bit more burn-out such that they maybe started off in general practice being enthusiastic, holistic, caring, et cetera, et cetera, and then it goes because they're human and the pressures are immense. Complementary medicine gives you another, it gives you another dimension. I think part of the burn-out is people getting a bit cynical, bored, tired...I think cynicism becomes a part of burn-out and I suppose it's a nice different skill, another attribute. (GP 11)
Earlier the analysis showed how CAM provided these GPs with a technical fix for conditions which remain untreatable with only the aid of conventional medicines. This feature of CAM is also a primary source of satisfaction for the doctors. Here the GPs draw upon the notion of the heart-sink patient (Jiwa 2000) which has been identified as producing feelings of helplessness amongst clinicians (Butler and Evans 1999). Indeed, the GP therapists promote the heart-sink patient from being a major cause of frustration and boredom to being a major source of challenge and stimulation for the GP:

I've been doing this same job now for thirty years or so, twenty years ago it was quite good to say let's look at it with new eyes, you do get bored you do get fed up...with the hypnosis instead of being fed up and bored stiff by patient $\mathrm{X}$ coming back in and telling me how uptight they were and how fed up they were you know how they couldn't sleep and all these things I had something to offer them... instead of them being a heart-sink patient because I couldn't treat their conditions they became somebody that maybe I could experiment on, this stimulated you to think about things that maybe you'd given up thinking about because you'd tried everything. (GP 17)

\section{Discussion}

Analysis of the GP therapists' accounts of their CAM reveals a number of practice benefits. The significance of these positive gains of CAM integration (filling gaps, providing safe interventions and relieving boredom) is heightened when considered alongside a number of challenges and issues currently facing the general practice community and when contextualized within the trends of CAM consumption and provision more broadly.

As we have seen, the GP therapists gain from employing a supplementary role for CAM in their wider treatment regime, a role which sits comfortably alongside the pragmatic approach of many CAM users (Astin, 1998; Berg and Arnetz, 1998; Eisenberg et al., 1998). It would appear that both CAM patients and GP therapists gain benefit from such a supplementary approach to CAM with both 
particularly willing to explore CAM where conventional treatments provide no relief.

Indeed, despite scientific and technological advances in health care, conventional medicine still encounters difficulties in treating a range of conditions particularly pertinent to general practice (ie. chronic illness) (Paterson and Britten, 1999). As the analysis illustrates, these GP therapists often fill the gaps in treatment left by conventional medicine through the introduction of CAM. Given the aging population of the UK and other developed societies and the increase in chronic illness accompanying such demographic change, the integration of CAM within the GP's surgery may well prove to be one increasingly attractive 'gap filler' for general practitioners frustrated by the lack of help their conventional treatments can offer large numbers of patients.

However, while it is the case that CAM is often good at providing some relief for symptoms associated with illness not well suited to conventional treatment (Zollman and Vickers, 1999c), this supplementary role does, nonetheless, also raise important questions about the style and ownership of CAM practice in wider patient care. Some within the nonmedical CAM community are keen to promote an holistic care approach which they see as moving beyond a supplementary gap-filling role for CAM, interpreting the medicines as generalist rather than specialist in scope (Cant and Calnan, 1991). Meanwhile, medical commentators have often been keen to question the validity of such generalist claims for CAM promoting general practice as the only safe environment for quality co-ordinated integrative care (Verhoef et al., 1999; Zollman and Vickers, 1999b). It would appear from the analysis here that GP therapists' understandings and experiences of integrative practice offer weight to this supplementary style approach highlighting the potential benefit of such an approach for medical practitioners.

Intertwined with such supplementary practice and in line with many CAM users (Douglas, 1994; Siahpush, 1999; Verhoef et al., 1998; Zollman and Vickers, 1999c), the GP therapists perceive CAM as on occasion offering a 'safer' treatment option than conventional medicine. This perception may initially appear to contrast with that of numerous medical commentators and researchers who have highlighted what they see as the potential dangers of CAM practice (Ernst, 1995; Ernst, 2002). How- ever, on closer inspection the GP therapists' perception of CAM (as offering a safe treatment option) does not necessarily run counter to the wider medical professions' concerns about the safety of CAM. For while illuminating the dangers of CAM practice the medical elite and other commentators have often been quick to qualify such warnings by promoting CAM practice by the medically trained (GP therapists) as one safeguard and means of minimizing the risk of CAM to unsuspecting patients (BMA, 1993).

Redirecting attention to conventional treatments, evidence suggests iatrogenic illness remains a major problem for the medical profession (Smith, 1998) particularly in relation to primary care where adverse drug reactions are a common reason for consultations (Millar, 2001). A growing number of patients are placing much higher priority upon medical risks and the adverse effects rather than the benefits of treatments (Gray, 1999) and, given the location of general practice as the prime interface between expert medical services and the patient (Busby etal., 1997), the integration of CAM may prove a valuable asset for GPs dealing with increasing numbers of patients fearful of the side effects associated with modern drug prescriptions (Keheller, 1994).

Primary care has experienced numerous bureaucratic and structural changes in recent years accelerated with the development of a Primary care focused health system (Department of Health, 1997). The contemporary NHS environment attracts criticism from consumers (Anon., 2001; Wright et al., 2000) and professionals alike (James, 2000) and some suggest primary care is currently prone to short term vision which 'undermines continuity and stability and leaves health professionals [disillusioned and] uncertain about their futures' (Dowell and Neal, 2000: 18). Given these circumstances it is not surprising that recent surveys suggest low morale and high levels of stress and job dissatisfaction amongst GPs (Appleton, House and Dowell, 1998; Mathie, 1997; Sibbald et al., 2000).

The analysis presented here suggests that some GPs view CAM as one possible means of counteracting these current difficulties with job satisfaction and morale. The therapies offer the GPs a different dimension to their practice which appears to rekindle their enthusiasm and interest in what would otherwise be frustrating and routine medical cases. This is an interesting finding considering the time, energy and 
resources currently allocated to combating the poor recruitment rates in general practice (Levenson and Edmans, 2001) and also the affects of stress on working GPs (Calnan et al., 2000). If the benefits of CAM integration become acknowledged by increasing numbers of GPs then it may be that this practice option provides one means of helping rebuild job satisfaction amongst GPs and of attracting medical students back to this branch of medical practice.

Acknowledging some of the limitations of conventional medical care and the frustration often experienced by contemporary GPs working in an ever more demanding health service (Dowell and Neal, 2000), it is reasonable to suggest the practice gains experienced by GP therapists will appear potentially attractive to a growing number of general practitioners and this can surely only serve to further encourage the direct integration of CAM within the general practice community.

However, it must be remembered that some within the medical community still oppose the integration of CAM and conventional practice, often on the grounds of a lack of an evidence base (Hunter, 2002; Leibovici, 1999), and the continuation and expansion of direct integration within the primary care setting will remain an issue of debate for some time to come. In the meantime, the practice gains experienced by GPs directly integrating CAM should be taken into serious consideration by health care providers, purchasers and managers contemplating the possible future practice and provision of these medicines within the primary care environment.

\section{References}

Adams, J. 2001a: Enhancing holism? GPs' explanations of their complementary practice. Complementary Health Practice Review 6, 193-204.

Adams, J. 2001b: Direct integrative practice, time constraints and reactive strategy: an examination of GP therapists' perceptions of their complementary medicine. Journal of Management in Medicine 15, 312-22.

Adams, J. 2000: General practitioners, complementary therapies and evidence-based medicine: the defence of clinical autonomy. Complementary Therapies in Medicine 8, 248-52.

Adams, J. and Tovey, P. 2000: Complementary medicine and primary care: towards a grassroots focus. In Tovey, P. editor, Contemporary primary care: the challenges of change. Buckinghamshire: Open University Press.

Anon. 2001: NHS arthritis care inadequate. The Guardian, Friday 20th April.
Appleton, K., House, A. and Dowell, A. 1998: A survey of job satisfaction, sources of stress and psychological symptoms among general practitioners in Leeds. British Journal of General Practice 48, 1059-63.

Anderson, E. and Anderson, P. 1987: General practitioners and alternative medicine. Journal of the Royal College of General Practice 37, 52-5.

Astin, J.A. 1998: Why patients use alternative medicine: results of a national study. Journal of the American Medical Association 279, 1533-48.

Berg, M. and Arnetz, B. 1998: Characteristics of users and nonusers of alternative medicine in dermatalogic patients attending a university hospital clinic. Journal of Alternative and Complementary Medicine 4, 277-9.

British Medical Association. 1993: Complementary medicine: new approaches to good practice. Oxford: Oxford University Press.

Botting, A. and Cook, R. 2000: Complementary medicine: Knowledge, use and attitudes of doctors. Complementary Therapies in Medicine 6, 41-7.

Busby, H., Williams, G. and Rogers, A. 1997: Bodies of knowledge: lay and biomedical understandings of musculoskeletal disorders. In M.A. Elston editor, The Sociology of Medical Science and Technology. Oxford: Blackwell.

Butler, C. and Evans, M. 1999: The 'heartsink' patient revisited. British Journal of General Practice 49, 230-3.

Calnan, M., Wainwright, D., Forsythe, M. and Wall, B. 2000: General practice. All stressed up and nowhere to go? Health Service Journal 110, 28-9.

Cant, S. and Calnan, M. 1991: On the margins of the medical marketplace? An exploratory study of alternative practitioners' perceptions. Sociology of Health and Illness 13, 39-57.

Department of Health (DoH). 1997: The New NHS: Modern Dependable. Cm 3087. London: The Stationary Office.

Douglas, M. 1994: The construction of the physician: a cultural approach to medical fashions. In S. Budd and U. Sharma editors, The Healing Bond: The Patient-Practitioner Relationship and Therapeutic Responsibility. London: Routledge.

Dowell, T. and Neal, R. 2000: Vision and change in primary care: past, present and future. In P. Tovey editor, Contemporary Primary Care: The Challenges of Change. Buckinghamshire: Open University Press.

Eisenberg, D.M., Davis, R.B., Ettner, S.L., Appel, S., Van Rompay, M. and Kessler, R.C. 1998: Trends in alternative medicine use in the United States, 1990-1997. Journal of the American Medical Association 280, 1569-75.

Ernst, E. 1995. Bitter pills of nature: safety issues in complementary medicine. Pain 60, 237-8.

Ernst, E. 2000: Prevalence of use of complementary medicine. A systematic review. Bulletin of the World Health Organisation 78, 252-7.

Ernst, E. 2002: Safety concerns about Kava. Lancet 359, 1865.

Featherstone, C. and Forsyth, L. 1997: Medical marriage. Forres, Scotland: Findshorn Press.

Fitzpatrick, R. and Boulton, M. 1994: Qualitative methods for assessing health care. Quality in Health Care 3, 107-113.

Primary Health Care Research and Development 2003; 4: 155-162 
Goldszmidt, M., Levitt, C., Duarto-Franco, E. and Kaczorowski, J. 1995: Complementary health care services: a survey of general practitioners' views. Canadian Medical Association Journal 153, 29-35.

Goldstein, M.S. and Glik, D. 1998: Use and satisfaction with homeopathy in a patient population. Alternative Therapies in Health and Medicine 4, 17-20.

Gray, J.A. 1999: Postmodern medicine. The Lancet 354, $1550-3$.

Hall, K. and Giles-Corti B. 2000: Complementary therapies and the general practitioner. Australian Family Physician 29, 602-6.

Hunter, M. 2002: Use of homeopathy in NHS not justified. British Medical Journal 324, 565.

House of Lords. 2000: Complementary and alternative medicine. London: House of Lords.

James, M.A. 2000: Doctors in the NHS. The Lancet 356, 859.

Jiwa, M. 2000: Frequent attenders in general practice: an attempt to reduce attendance. Family Practice 17, 248-51.

Keheller, D. 1994: Self-help groups and their relationship to medicine. In Gabe, J., Keheller, D. and Williams, G. editors, Challenging Medicine. London: Routledge.

Leibovici, L. 1999: Alternative (complementary) medicine: a cuckoo in the nest of empiricist reed warblers. British Medical Journal 319, 1629-32.

Levenson, R. and Edmans, T. 2001: NHS staffing. Way to go. Health Service Journal 111, 26-7.

Mathie, D. 1997: The primary care workforce crisis: a time for decisive action. British Journal of General Practice 47, 3-4.

May, C. and Sirur, D. 1998: Art, science and placebo: incorporating homeopathy in general practice. Sociology of Health and Illness 20, 168-90.

McGregor, K.J. and Peay, E.R. 1996: The choice of alternative therapy for health care: testing some propositions. Social Science and Medicine 43, 1317-27.

Millar, J.S. 2001: Consultations owing to adverse drug reactions in a single practice. British Journal of General Practice 51, 130-1.

Paterson, C. and Britten, N. 1999: Doctors can't help much: the search for an alternative. British Journal of General Practice 49, 626-9.

Perkin, M., Pearcy, R.M. and Fraser, J.S. 1994: A comparison of the attitudes shown by general practitioners, hospital doctors and medical students towards alternative medicine. Journal of the Royal Society of Medicine 87, 523-5.

Peters, D. 1994: Sharing responsibility for patient care. In S. Budd and U. Sharma editors, The healing bond: the patientpractitioner relationship and therapeutic responsibility. London: Routledge.

Pirotta, M., Cohen, M., Kotsirilos, V. and Farish, S. 2000: Complementary therapies: have they become accepted in general practice? Medical Journal of Australia 172, 105-9.

Rice, P. and Ezzy, D. 1999: Qualitative research methods: A health focus. Oxford: Oxford University Press.

Seale, C. 1998: Researching society and culture. London: Sage.

Siahpush, M. 1999: A critical review of the sociology of alternative medicine: research on users, practitioners and the orthodoxy. Health 4, 159-72.
Siahpush, M. 1998: Postmodern attitudes about health: a population-based exploratory study. Complementary Therapies in Medicine 7, 164-9.

Sibbald, B., Enzer, I., Cooper, C., Rout, U. and Sutherland, V. 2000: GP job satisfaction in 1987, 1990 and 1998: lessons for the future? Family Practice 17, 364-71.

Smith, R. 1998: Renegotiating medicines' contract with patients. British Medical Journal 316, 1622-3.

Thomas, K., Nicholl, J.P. and Fall, M. 2001: Access to complementary medicine via general practice. British Journal of General Practice 51, 25-31.

Thomas, K., Nicholl, J.P. and Coleman, P. 2001: Use and expenditure on complementary medicine in England: a population based survey. Complementary Therapies in Medicine 9, 2-11.

Tovey, P. editor, 2000: Contemporary primary care: the challenges of change. Buckinghamshire: Open University Press.

Tovey, P. and Adams, J. 2002: Towards a sociology of CAM and nursing. Complementary Therapies in Nursing and Midwifery $8,12-16$.

Tovey, P. and Adams, J. 2001: Primary care as intersecting social worlds. Social Science and Medicine 52, 695-706.

Verhoef, M., White, M. and Doll, R. 1999: Cancer patients' expectations of the role of family physicians in communication about complementary therapies. Cancer Prevention and Control 3, 181-7.

Verhoef, M., Scott, C. and Hilsden, R. 1998: A multimethod research study on the use of complementary therapies among patients with inflammatory bowel disease. Alternative Therapies in Health and Medicine 4, 68-71.

Verhoef, M. and Sutherland, L. 1995: Alternative medicine and general practitioners. Canadian Family Physician 41, 1005-11.

Vincent, C. and Furnham, A. 1996: Why do patients turn to complementary medicine? British Journal of Clinical Psychology 35, 37-48.

Visser G. and Peters, L. 1990: Alternative medicine and general practitioners in the Netherlands: towards acceptance and integration. Family Practice 7, 227-32.

Wearn, A.M. and Greenfield, S.M. 1998: Access to complementary medicine in general practice: survey in one UK health authority. Journal of the Royal Society of Medicine 91, 46570.

White, A., Resch, K.L. and Ernst, E. 1997: Complementary medicine: use and attitudes among GPs. Family Practice 14, 302-6.

Wright, J., Quasim, T. and Booth, M. 2000: Doctors write on patients' eye view of quality. Longer consultation time that patients wish for is not available in NHS. British Medical Journal 320, 511.

Zollman, C. and Vickers, A. 1999a: ABC of complementary medicine. Complementary medicine in conventional practice. British Medical Journal 319, 901-4.

Zollman, C. and Vickers, A. 1999b: Complementary medicine and the doctor. British Medical Journal 319, $1558-61$.

Zollman, C. and Vickers, A. 1999c: Complementary medicine and the patient. British Medical Journal 319, 1486-9. 